\section{POS0431 FIBROBLASTS ARE NOT JUST FIBROBLASTS - CLEAR DIFFERENCES IN ECM PRODUCTION BETWEEN DERMAL AND LUNG FIBROBLASTS IN RESPONSE TO GROWTH FACTORS}

S. F. Madsen ${ }^{1,2}$, A. S. Siebuhr ${ }^{2}$, H. Jessen ${ }^{3}$, J. M. B. Sand ${ }^{3}$, M. Karsdal ${ }^{4}$, A. C. Bay-Jensen ${ }^{2}{ }^{1}$ University of Copenhagen, Department of Biomedical Sciences, Copenhagen, Denmark; ${ }^{2}$ Nordic Bioscience, ImmunoScience, Biomarkers and Research, Herlev, Denmark; ${ }^{3}$ Nordic Bioscience, Respiratory Research, Biomarkers and Research, Herlev, Denmark; ${ }^{4}$ Nordic Bioscience, Biomarkers and Research, Herlev, Denmark

Background: Many systemic sclerosis (SSc) patients develop lung fibrosis, which contribute significantly to increased mortality ${ }^{1}$. Activated and proliferating fibroblasts are responsible for the excessive extracellular matrix (ECM) formation and stiffening of the connective tissue leading to skin and lung fibrosis. There is currently no effective treatment for the fibrosis in SSc and there is therefore a medical need for further understanding the pathogenesis of fibrosis. Fibrosis is associated with different growth factors, including tumor growth factor beta 1 (TGF- $\beta 1$ ) and platelet derived growth factor-ab (PDGF-ab) ${ }^{2}$

Objectives: We investigated how stimulation with TGF- $\beta 1$ and PDGF-ab affected the migration capacity and the ECM production using translational biomarkers of type I, III and VI collagens in healthy human dermal and lung fibroblasts.

Methods: The fibroblasts were grown in DMEM media containing $0.4 \%$ fetal calf serum, ficoll (to produce a crowded environment) and ascorbic acid for up to 12 days. The cells were stimulated with TGF- $\beta 1$ [0.04-1 nM] or PDGF-ab [3 nM] at treatment initiation and changed twice a week. Non-stimulated fibroblasts (w/o) were used as control. A wound was induced by scratching the cells at day 1 after treatment initiation and the migration was followed for 2 days. Type I, III and VI collagen formation (PRO-C1, PRO-C3 and PRO-C6, respectively) were evaluated by validated ELISAs (Nordic Bioscience) in supernatant from day 0, 4, 8 and 12. Statistical analysis included 2-way ANOVA and Dunnett's test.

Results: The PDGF-ab stimulated dermal fibroblasts migrated significantly more than the non-stimulated $(p<0.0001)$ and TGF- $\beta 1$ stimulated $(p<0.001)$ dermal fibroblasts 48 hours after the scratch (migration app. $70 \%, 30 \%$ and $30 \%$ respectively). There was no difference between the migration of the non-stimulated, TGF- $\beta 1$ and PDGF-ab stimulated lung fibroblasts after 48 hours, as all migrated to approximately $70 \%$.

TGF- $\beta 1$ stimulation led to a significant increase in type I collagen formation (PRO-C1) in both dermal and lung fibroblasts from day 4 and onwards compared to $w / o(p<0.0001)$. TGF- $\beta 1$ also lead to a significant increase in type III collagen formation (PRO-C3) from day 8 in lung fibroblasts compared to $w / o(p<0.0001)$. PDGF-ab stimulation led to a significant increase in type III collagen formation in dermal fibroblasts from day 8 compared to w/o $(p<0.0001)$. PDGF-ab stimulation led to a significant increase in type VI collagen formation (PRO-C6) in both dermal and lung fibroblasts from day 4 and onwards compared to $w / o(p<0.0001)$. Conclusion: PDGF-ab increased the migration activity of the dermal fibroblasts, where the lung fibroblasts had a general high migration activity. The dermal and lung fibroblasts showcase the same ECM production within both type I and type VI collagen formation. The two fibroblasts types did however react opposite each other regarding the type III collagen formation: the dermal fibroblasts responded to PDGF-ab stimulation, where the lung fibroblasts responded to the TGF- $\beta 1$ stimulation. The clear differences in the ECM production between the dermal and lung fibroblasts can be important in the search for an effective treatment for fibrosis in SSc and related lung fibrosis.

\section{REFERENCES:}

[1] McNearney, T. A. et al. Pulmonary involvement in systemic sclerosis: Associations with genetic, serologic, sociodemographic, and behavioral factors. Arthritis Care Res. 57, 318-326 (2007).

[2] Wynn, T. A. Common and unique mechanisms regulate fibrosis in various fibroproliferative diseases. J. Clin. Invest. 117, 524-529 (2007).
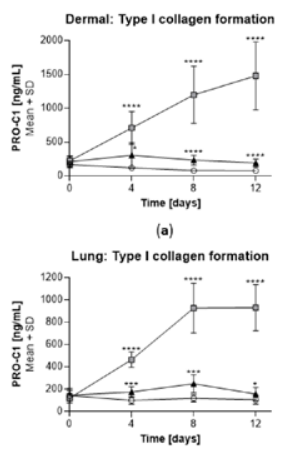

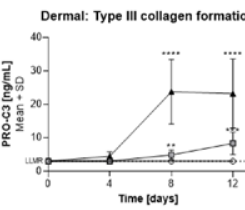

(b)

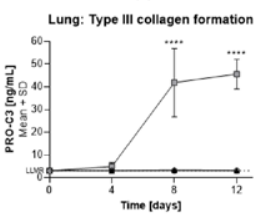

(e)
- w/o - TGF- $\beta 1+$ PDGF-ab
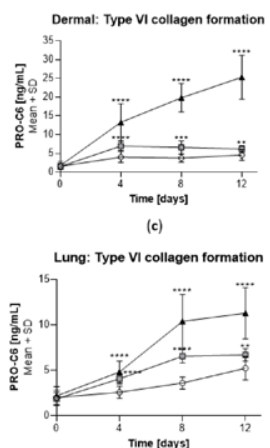

Figure 1. TGF- $\beta 1$ and PDGF-ab can stimulate ECM production in both dermal and lung fibroblasts. Synthesis of type I (ai) III (b), VI (c) collagen in dermel fibroblasts and type I (d), III (e), Vi (f) collagen in lung fibroblasts. Data are shown as mean comparisons test against the control (w/
Disclosure of Interests: Sofie Falkenløve Madsen Employee of: Nordic Bioscience and University of Copenhagen, Anne Sofie Siebuhr Employee of: Nordic Bioscience A/S, Henrik Jessen: None declared, Jannie Marie Bülow Sand Employee of: Nordic Bioscience A/S, Morten Karsdal Shareholder of: Nordic Bioscience A/S, Employee of: Nordic Bioscience A/S, Anne-Christine Bay-Jensen Shareholder of: Nordic Bioscience A/S, Employee of: Nordic Bioscience A/S DOI: 10.1136/annrheumdis-2021-eular.3643

\section{\begin{tabular}{|l|l}
\hline POS0432 & POST-IMMUNIZATION WITH COLLAGEN V CONFERS
\end{tabular} A DISADVANTAGEOUS IMMUNE MATRICES MICROENVIRONMENT FOR EARLY LUNG FIBROSIS IN A SSC MOUSE MODEL}

V. Elias ${ }^{1}$, Z. Queiroz ${ }^{1}$, S. Catanozi ${ }^{2}$, A. Santos Filho' ${ }^{1}$, S. Fernezlian ${ }^{3}$, A. P. Velosa' ${ }^{1}$, P. D. Sampaio-Barros ${ }^{1}$, V. Capelozzi ${ }^{3}$, W. Teodoro ${ }^{1} .{ }^{1}$ University of São Paulo, Division of Rheumatology, São Paulo, Brazil; ${ }^{2}$ University of São Paulo, Division of Endocrinology, São Paulo, Brazil; ${ }^{3}$ University of São Paulo, Department of Pathology, São Paulo, Brazil

Background: The autoimmunity and inflammation phenomena observed in systemic sclerosis (SSc) lead to the dysregulation of type $\mathrm{V}$ collagen (Col V) and extracellular matrix (ECM) deposition of Col V, collagen I (Col I) and collagen III (Col III) fibers, characteristic of pulmonary fibroproliferative disease. T cells are the predominant inflammatory infiltrate in the lungs and are believed to produce cytokines that drive the synthesis of matrix proteins by fibroblasts, resulting in excessive fibrosis Although most studies to date have focused on CD4+T and CD20+ B immune cells in some SSc subsets, cytotoxic CD8+ T cells are also involved in the pathogenesis of SSc. We previously reported that reactivity to the ColV-self antigen predicts late SSc lung fibrosis in mice immunized with Col V after 120 days; however, the profile of underlying immune matrices in early SSc lung fibrosis remains unclear. Objectives: To quantify T and B-cells and collagen fibers in the days following immunization with Col V in a mouse model mimicking human lung involvement in SSc.

Methods: Female C57BL/6 mice $(n=18)$ were immunized subcutaneously with human Col V $(150 \mu \mathrm{g})$ in complete Freund's adjuvant, followed by two intramuscular boosters (IM-COLV). The control group $(n=18)$ did not receive Col V. Three groups of animals ( $n=6$ each) were euthanized on days 15,30 and 45 after immunization. The lung sections were fixed in $10 \%$ buffered formalin, embedded in paraffin, and sectioned at $4 \mu \mathrm{m}$. Immunohistochemistry, immunofluorescence and histomorphometry were performed to phenotype and quantify CD4 and CD8 T-cells, CD20 B-cells, and Col I, III and V, respectively.

Results: We found that T-cells $\left(\mathrm{CD}^{+}\right)$, cytotoxic $\mathrm{T}$ cells $\left(\mathrm{CD}^{+}\right)$, and B-cells $\left(\mathrm{CD} 20^{+}\right)$were present in high densities in the lungs of IM-COLV mice, with variation in the absolute abundance of each of these immune cell lineages at 15, 30 and 45 days after immunization with Col V. In fact, a significantly higher density of $\mathrm{CD}^{+}, \mathrm{CD}^{+}$, and $\mathrm{CD} 2 \mathrm{O}^{+}$was detected early along the connective matrix of alveolar septa at 15 days after Col $\mathrm{V}$ immunization. In addition, higher density of Col I, III and V fibers were also observed early (Table 1). Although early SSclung fibrosis is generally considered to be linked to inflammatory cytokines, we also infer that cytotoxic T-cells may induce alveolar cells apoptosis by triggering kinases on macrophages and then accelerate fibrotic scar.

Conclusion: Our study quantitatively establishes that the densities of CD4+ CD8+ and CD20+, as well as Col I, Col III and Col V can be characterized as markers of early lung fibrosis in SSc. These findings suggest that cytotoxic $\mathrm{T}$ cells may induce apoptosis and secrete profibrotic cytokines to induce the deposition of collagen fibers in the lungs, inferring that early B cell depletion may improve early lung fibrosis in SSc.

\begin{tabular}{|c|c|c|c|c|c|c|}
\hline & \multicolumn{4}{|c|}{ Post-Col V Immunization (Days) } & & \\
\hline & \multicolumn{2}{|c|}{15} & \multicolumn{2}{|c|}{30} & \multicolumn{2}{|c|}{45} \\
\hline & Control & IM-COLV & Control & IM-COLV & Control & IM-COLV \\
\hline \multicolumn{7}{|l|}{ Immune Cells } \\
\hline $\begin{array}{l}\text { CD4+ cells/ } \\
\mathrm{mm}^{2}(\%)\end{array}$ & $\begin{array}{c}13.85 \pm \\
0.46\end{array}$ & $\begin{array}{c}34.14 \pm \\
1.55^{\star}\end{array}$ & $\begin{array}{c}12.63 \pm \\
0.56\end{array}$ & $\begin{array}{r}23.38 \pm \\
0.83\end{array}$ & $\begin{array}{c}14.32 \pm \\
0.52\end{array}$ & $\begin{array}{c}23.62 \pm \\
0.40\end{array}$ \\
\hline $\begin{array}{r}\text { CD8+ cells/ } \\
\mathrm{mm}^{2}(\%)\end{array}$ & $\begin{array}{c}13.84 \pm \\
0.60\end{array}$ & $\begin{array}{r}39.40 \pm \\
0.99^{\star *}\end{array}$ & $\begin{array}{c}12.42 \pm \\
0.52\end{array}$ & $\begin{array}{r}22.87 \pm \\
0.85\end{array}$ & $\begin{array}{c}12.93 \pm \\
0.57\end{array}$ & $\begin{array}{c}23.07 \pm \\
1.00\end{array}$ \\
\hline $\begin{array}{l}\text { CD20+ cells/ } \\
\text { mm }^{2}(\%)\end{array}$ & $\begin{array}{c}12.12 \pm \\
1.01\end{array}$ & $\begin{array}{l}33.84 \pm \\
1.43^{\#}\end{array}$ & $\begin{array}{c}11.70 \pm \\
1.14\end{array}$ & $\begin{array}{c}15.23 \pm \\
6.70\end{array}$ & $\begin{array}{c}12.46 \pm \\
0.50\end{array}$ & $\begin{array}{c}28.24 \pm \\
0.67\end{array}$ \\
\hline \multicolumn{7}{|l|}{ Collagen Fibers } \\
\hline $\begin{array}{l}\text { Col V (area } \\
\text { fraction) }\end{array}$ & $\begin{array}{c}0.05 \pm \\
0.003\end{array}$ & $\begin{array}{c}0.12 \pm \\
0.01\end{array}$ & $\begin{array}{l}0.08 \pm \\
0.003\end{array}$ & $\begin{array}{l}0.14 \pm \\
0.01^{t+}\end{array}$ & $\begin{array}{l}0.07 \pm \\
0.003\end{array}$ & $\begin{array}{l}0.11 \pm \\
0,003\end{array}$ \\
\hline Col I (area & $0.16 \pm$ & $0.38 \pm$ & $0.14 \pm$ & $0.25 \pm$ & $0.15 \pm$ & $0.24 \pm$ \\
\hline fraction) & 0,01 & $0.05^{\# \#}$ & 0.01 & 0.03 & 0.02 & 0.01 \\
\hline Col III (area & $0,16 \pm$ & $0.28 \pm$ & $0.14 \pm$ & $0.25 \pm$ & $0.13 \pm$ & $0.16 \pm$ \\
\hline fraction) & 0,003 & $0.01^{\dagger}$ & 0.004 & 0.05 & 0,007 & 0.02 \\
\hline Total Col $\mu \mathrm{g} / \mathrm{mg}$ & $\begin{array}{r}2.7 \pm \\
0.29\end{array}$ & $\begin{array}{c}3.99 \pm \\
0.58\end{array}$ & $\begin{array}{c}3.15 \pm \\
0.19\end{array}$ & $\begin{array}{c}3.77 \pm \\
0.27\end{array}$ & $\begin{array}{c}2.87 \pm \\
0.30\end{array}$ & $\begin{array}{c}4.99 \pm \\
0.60\end{array}$ \\
\hline
\end{tabular}

Data are shown as mean \pm SD. Comparisons were done using ANOVA/Dunn's Multiple comparison test $\mathrm{P}<0.05)$. ${ }^{*} 15$ vs 30 and 45 days; ** 15 vs 30 and 45 days; ${ }^{\#} 15$ vs 30 and 45 days; ${ }^{\# \#}$ 15 vs 30 and 45 days; ${ }^{\dagger} 15$ vs 45 days; ${ }^{\dagger+} 30$ vs 45 days. Col I, collagen type I; Col III, collagen type III; Col V, collagen type V. 
Disclosure of Interests: Vitoria Elias: None declared, Zelita Queiroz: None declared, Sergio Catanozi: None declared, Antonio Santos Filho: None declared, Sandra Fernezlian: None declared, Ana Paula Velosa: None declared, Percival D. Sampaio-Barros Speakers bureau: Actelion, Boehringer Ingelheim, Abbvie, Lilly, Novartis, Consultant of: Abbvie, Bayer, Boehringer Ingelheim, Lilly, Novartis, Pfizer, Vera Capelozzi: None declared, Walcy Teodoro: None declared

DOI: 10.1136/annrheumdis-2021-eular.3663

\section{POS0433 CAN INTERLEUKIN 33 (IL-33) BE CONSIDERED A VALUABLE BIOMARKER IN THE EARLY STAGES OF SYSTEMIC SCLEROSIS? ANALYSIS OF A MONOCENTRIC COHORT}

C. Angelelli ${ }^{1}$, K. Stefanantoni ${ }^{1}$, M. Cadar ${ }^{1}$, G. Pellegrino ${ }^{1}$, F. Conti ${ }^{1}$, V. Riccieri ${ }^{1}$. ${ }^{1}$ Sapienza University of Rome, Scienze cliniche internistiche, anestesiologiche e cardiovascolari, Roma, Italy

Background: The ScS approach has changed considerably in recent years especially concerning the very early diagnosis of the disease (VEDOSS) at the time when the patient is still in an undifferentiated form (UCTD) at risk of developing SSc $(1,2)$. Of great value are different clinical, instrumental and laboratory findings, such as specific autoantibodies and Nailfold VideoCapillaroscopy (NVC), able to identify those cases progressing into overt SSc. IL-33 cytokine is known to exert pro-fibrotic effects through its membrane receptor ST2 on immune cells and myofibroblasts and recent studies suggest that it can be released following endothelial cell activation at the onset of SSc $(3,4)$

Objectives: Our aim has been to evaluate IL-33 serum levels in a monocentric cohort of VEDOSS patients, looking for the possible association with clinical phenotype and disease progression, focusing on the microvascular capillaroscopic changes.

Methods: Fourty-seven VEDOSS patients underwent a complete clinical, instrumental and laboratory evaluation, including NVC and specific SSc autoantibodies. At baseline serum IL-33 levels were measured using an ELISA assay. In 32 of them we also had a second serum sample at a follow-up time of at least 24 months (range 24 to 96 months).

Results: During the follow-up time, 17 patients were subsequently reclassified as having ScS whereas 30 remained VEDOSS. The "progressor" subjects positively correlated with the presence of anti-Topoisomerase I antibodies ( $p>0,004)$. IL-33 concentrations had a median value of $427.2 \mathrm{pg} /$ $\mathrm{ml}$ (IQR $967.9 \mathrm{pg} / \mathrm{ml}$ ) at baseline and of $130.4 \mathrm{pg} / \mathrm{ml}$ (IQR $399 \mathrm{pg} / \mathrm{ml}$ ) at the follow up, showing a statistically significant difference independently from the progression of the disease $(p=0.03)$. Besides significantly higher levels were detected in those patients with more severe NVC changes, defined as "active" pattern $(\mathrm{p}<0.05)$. Among the 47 VEDOSS patients, 12 started some kind of vascular therapy. In these patients serum IL-33 concentrations significantly lowered during the follow-up respect to those without any treatment $(p<0.03)$

Conclusion: The analysis of our data confirms previous report (5) on higher IL-33 serum levels in the very early stages of UCTD patients at risk for SSc, regardless of their progression in established SSc, although related to more severe microvascular NVC involvement. The lowering of IL-33 serum levels that we detected in the follow up of our patients, may be linked to the well-known endothelial changes during the progression of the SSc and seems also to be partially affected by treatments. Investigation on a greater number of patients are needed to better understand our findings.

REFERENCES:

[1] J. Avouac et al. Ann Rheum Dis 2011

[2] G Valentini et al. Clin Exp Med 2017

[3] Manetti M, et al. Ann Rheum Dis 2010

[4] Terras S et al. Ann Rheum Dis 2013

[5] Vettori S, et al. J Clin Immunol 2014

Disclosure of Interests: None declared

DOI: 10.1136/annrheumdis-2021-eular.4196

\section{Basic and translational pain science}

POS0434

CLINICAL UTILITY OF SCREENING TOOLS IN REFERRAL OF PATIENTS WITH HAND ARTHRALGIA TO RHEUMATOLOGISTS

G. Figueroa-Parra ${ }^{1}$, D. Vega-Morales ${ }^{1}$, P. Herrera-Sandate ${ }^{1}$, J. A. Esquivel Valerio $^{1}$, B. R. Vázquez Fuentes ${ }^{1}$, M. A. Garza Elizondo ${ }^{1}$, Y. G. Ordoñez Azuara $^{2}$, R. F. Gutierrez-Herrera ${ }^{2}$, D. Á. Galarza-Delgado ${ }^{1} .{ }^{1}$ Hospital
Universitario Dr. José Eleuterio González, Rheumatology Service, Monterrey, Mexico; ${ }^{2}$ Hospital Universitario Dr. José Eleuterio González, Family Medicine Department, Monterrey, Mexico

Background: Clinically Suspect Arthralgia (CSA) was defined by European League Against Rheumatism to identify a combination of clinical features that best characterise patients with arthralgia who are at risk of progression to rheumatoid arthritis (RA) (1). A specificity $>90 \%$ is obtained with the presence of $\geq 4$ parameters. Another clinical feature useful to identify patients at risk is the squeeze test (ST). Recently, we have identified the necessary strength to screen the patient with arthralgia through ST, with a median squeeze force of $3 \mathrm{~kg}$ and $2.78 \mathrm{~kg}$ to evoke pain in the right and left hand of the RA patient, respectively (2). Primary care physicians (PCP), the first contact of patients at risk, could benefit from these screening tools, prompting early referral, diagnosis, and treatment of these individuals. Objectives: To identify the clinical utility of CSA and ST in the referral of patients with hand arthralgia from PCP to rheumatologists.

Methods: We conducted a cohort study from October 2018 to December 2020 in 110 patients who attended a Family Medicine clinic at University Hospital "Dr. Jose Eleuterio Gonzalez" in Monterrey, Mexico. We recruited patients with hand arthralgia with no history of previous trauma or autoimmune rheumatic diseases. A questionnaire assessing CSA criteria was employed, and an ST maneuver was performed through an automated compressor with quantitative measures of applied force. Patients were grouped based on referral to Rheumatology consultation and variables categorized according to clinically relevant thresholds. Chi square test was performed in categorical variables, t-student test was performed in normal, continuous variables and Spearman's rho correlation was utilized between CSA number of criteria and quantitative ST force using SPSS v25.

Results: Out of 110 patients, 49 (44.5\%) were referred to a rheumatologist. A non-significant association was found across assessed variables in referred and non-referred patients as seen in Table 1. Spearman's rho found a moderate correlation between the number of CSA criteria and quantitative force in right $(r=-.445)$ and left $(r=-.382)$ hand as seen in Figure 1. Evaluation of CSA cutoffs other than $\geq 4$ did not yield a significant association in referral of patients to the rheumatologist (data not shown)

Conclusion: The clinical utility of CSA criteria and ST in referral of patients with hand arthralgia from PCP to rheumatologists is currently limited. More research is needed to elucidate the clinical utility of these screening tools.

\section{REFERENCES:}

[1] van Steenbergen HW, et al. EULAR definition of arthralgia suspicious for progression to rheumatoid arthritis. Ann Rheum Dis. 2017;76(3):491-496.

[2] Vega-Morales D, et al. Automated squeeze test (Gaenslen's manoeuvre) to identify patients with arthralgia suspicious for progression to RA: improving time delay to rheumatology consultation. Ann Rheum Dis. 2017;76(10):e40.

Table 1. Demographic characteristics and clinical performance of CSA and ST in referral of patients with hand arthralgia from PCP to rheumatologists.

\begin{tabular}{lccc}
\hline & $\begin{array}{c}\text { Referred patients, } \\
\mathbf{n}=\mathbf{4 9}\end{array}$ & $\begin{array}{c}\text { Non-referred patients, } \\
\mathbf{n}=\mathbf{6 1}\end{array}$ & $p$ \\
\hline Female, $\mathrm{n}(\%)$ & $40(81.6)$ & $50(82.0)$ & 0.964 \\
Age in years, mean \pm SD & $46.76 \pm 14.43$ & $52.05 \pm 15.00$ & 0.064 \\
Patients with $\geq 4$ CSA criteria, $\mathrm{n}(\%)$ & $23(46.9)$ & $19(31.1)$ & 0.090 \\
Right hand positive ST patients, $\mathrm{n}(\%)$ & $21(42.9)$ & $22(36.1)$ & 0.468 \\
Left hand positive ST patients, $\mathrm{n}(\%)$ & $26(53.1)$ & $28(45.9)$ & 0.455 \\
Force in right hand ST, mean kg \pm SD & $4.19 \pm 2.92$ & $3.86 \pm 3.07$ & 0.571 \\
Force in left hand ST, mean kg \pm SD & $4.25 \pm 3.04$ & $3.54 \pm 2.74$ & 0.198 \\
\hline
\end{tabular}

$\begin{array}{lll}\text { Force in left hand ST, mean } \mathrm{kg} \pm \mathrm{SD} & 4.25 \pm 3.04 & 3.54 \pm 2.74\end{array}$

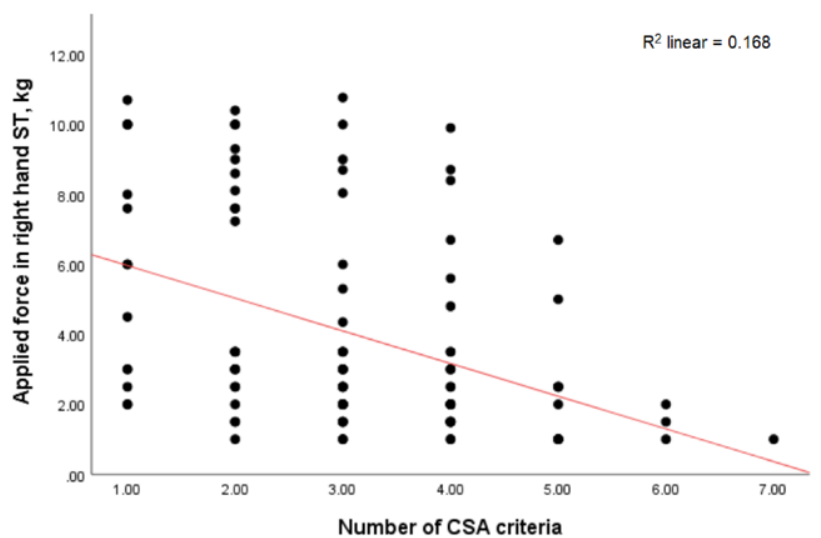

Figure 1. Scatter plot showing a moderate correlation between the number of CSA criteria and applied force in the right hand ST in $\mathrm{kg}$, Spearman's rho $=-.445$.

Disclosure of Interests: None declared

DOI: 10.1136/annrheumdis-2021-eular.3754 